\title{
SOBRE O “JARDiM dAS DElícias” COMO MODElo de ANÁlise DOS PROCESSOS DE COMUNICAÇÃO INTERCULTURAL
}

\author{
Lurdes Macedo
}

\begin{abstract}
Resumo
A observação do tríptico "Jardim das Delícias", de Hieronymus Bosch constitui o ponto de partida para um curto ensaio sobre a possível interpretação desta obra por parte do seu último comprador, Filipe II de Espanha. Por sua vez, este ensaio conduz à proposta de um modelo, baseado em três categorias de análise, para a interpretação crítica do percurso global que a humanidade tem vindo a trilhar desde o início das grandes navegações intercontinentais, inicialmente levadas a cabo por portugueses e espanhóis. O modelo proposto pretende constituir um contributo para a desfragmentação da memória de um longo processo marcado pela tensão entre forças hegemónicas e dinâmicas de interculturalidade.
\end{abstract}

\section{Palavras-chave}

Comunicação intercultural; desfragmentação da memória; globalização

\begin{abstract}
The observation of Hieronymus Bosch's "Garden of Delights" triptych is the starting point for a short essay on the possible interpretation of this work by its last purchaser, Philip II of Spain. Additionally, this essay leads to the proposal of a model, based on three categories of analysis, for the critical interpretation of the global course that humanity has been taking since the beginning of the great intercontinental navigations, initially carried out by the Portuguese and the Spanish. The proposed model intends to contribute to the defragmentation of the memory of a long process marked by the tension between hegemonic forces and dynamics of interculturality.
\end{abstract}

Keywords

Defragmentation of memory; globalization; intercultural communication

\section{INTRODUÇÃo: Do “JARDim dAS Delícias” À DIVERSIDAdE DO MUNDO}

Ao contemplar o tríptico "Jardim das Delícias", da autoria de Hieronymus Bosch exposto atualmente no Museu do Prado, em Madrid -, o observador encontra-se perante uma das mais sugestivas obras de arte quinhentista. Embora não se saiba com exatidão em que data foi pintado este "Jardim das Delícias", vários especialistas apontam como certo que Bosch se terá dedicado a esta obra num período indeterminado compreendido entre 1500 e 1505 (Portús, 2008).

Inspirada em fontes iconográficas tão distintas como a religião, a alquimia, o esoterismo ou o imaginário fantástico, a pintura é composta por três painéis distintos, 
mas interligados entre si, apresentando uma complexa narrativa que, como refere Bosing (2003), tem suscitado as mais diversas interpretações ao longo dos últimos cinco séculos.

Tal como em outras obras do período de maturidade do autor, encontra-se neste tríptico uma virtude rara na pintura da época: à tradição medieval da pintura flamenga do século $\mathrm{XV}$, baseada no equilíbrio e na harmonia, foi aliada a sensibilidade moderna do século XVI, propensa ao despertar da espiritualidade e da razão (AAVV, 2006). Trata-se, portanto, de uma obra inscrita num período de charneira, na qual se pode observar uma nova abordagem de representação pictórica. Daí que, no seu tempo, a arte de Bosch fosse considerada extravagante, sendo o seu público circunscrito, como refere Portús (2008, p. 320), "a uma elite com a formação necessária para a interpretar".

Filipe II de Espanha, educado como um verdadeiro príncipe renascentista - e, consequentemente, tendo vindo a tornar-se num homem culto e curioso (Magalhães, 1993) -, terá compreendido a dimensão intelectual associada à arte do pintor e adquiriu, entre outras obras de Bosch, este "Jardim das Delícias", levando-o para o Escorial em 1593. Considerando, tal como Mukarovsky (1997) propôs, que a arte pode ser comparável a um diálogo no qual os interlocutores são o autor e o fruidor, atentemos nesta obra perpetuada pelos contínuos esforços de interpretação ao longo do tempo, sem perder de vista a enigmática interação entre o genial pintor de imaginários e o monarca de dimensão planetária.

O tríptico começa por exibir, no verso dos painéis volantes, quando fechados sobre o painel central, "A Criação do Mundo" numa representação do seu terceiro dia. Uma vez abertos os painéis volantes, forma sob a qual a obra se encontra exposta ao público, a narrativa prossegue com uma imagem do Paraíso na frente do painel esquerdo. Num cenário idílico, o Criador, aqui representado de forma mais jovial do que em outras pinturas de Bosch, apresenta Eva a Adão. Segundo as Sagradas Escrituras, este foi o momento em que Deus abençoou o primeiro casal humano com o mandamento: "sejam férteis e multipliquem-se. Encham e subjuguem a Terra!" (Génesis, 1, p. 28). Esta vontade primordial de Deus, a de que a partir de Adão e Eva a espécie humana se reproduzisse e se espalhasse por todo o planeta, garantiria assim um mundo amplamente habitado.

O painel central da obra é fixo e de maior dimensão. Neste encontra-se representado o jardim das delícias terrenas, onde vários grupos de figuras humanas desnudadas se deleitam numa cena erótica carregada de forte simbolismo. A pintura é dominada por uma ampla espacialidade na qual as figuras podem ser observadas como se de uma vista aérea se tratasse. De destacar que esta forma de representação do espaço configura uma exceção no panorama artístico da época.

Ao centro da composição encontra-se a fonte da juventude, representada em forma de círculo, onde se banha um grupo composto por numerosas mulheres caucasianas com diferentes tons de pele, assim como por algumas mulheres negras. A forma circular da fonte da juventude é reforçada pela disposição em que se encontram os cavaleiros que a rodeiam. Estes homens, montados em animais tão diferentes como cavalos, ursos, javalis, camelos, tigres e avestruzes - sempre representados sob o signo 
do fantástico - carregam peixes e frutos silvestres de dimensões extraordinárias. De salientar que estes dois elementos, que se julga representarem símbolos do prazer carnal na Flandres do tempo de Bosch, se encontram um pouco por todo o painel.

Acima da fonte da juventude observa-se um grande lago denominado pela fonte do adultério. Ao centro desta outra fonte, num enorme globo cinzento, personagens luxuriosas dedicam-se a acrobacias lascivas. Figuras humanas, sobretudo brancas mas também algumas negras, bem como figuras fantásticas, banham-se nesta fonte enquanto se divertem em jogos aquáticos. A fonte do adultério é envolvida por edificações inverosímeis e por elementos vegetais, entre os quais sobressaem verdes arbustos, que Ihe conferem um ambiente idêntico aos que se podem observar na pintura surrealista do século XX. Daí que autores como Quina (2005) afirmem que o "Jardim das Delícias" constituiu uma obra de referência para artistas envolvidos nas correntes contemporâneas antinaturalista e surrealista.

A parte inferior do jardim das delícias terrenas é ocupada por vários grupos de homens e mulheres que, ora dedicados a jogos amorosos, ora dedicados à colheita e à degustação de frutos vermelhos sobredimensionados, se comprazem de forma livre e despudorada. Entre as personagens, maioritariamente caucasianas, podem observar-se mais uma vez alguns negros. Destacam-se, à esquerda, num cenário aquático, vários casais de apaixonados em cenas improváveis: um deles namora dentro de uma esfera de cristal'; outro navega numa enorme concha enquanto procura subtrair uma amora gigante a um grupo que se dedica a jogos lúdicos; um outro casal parece dançar com as pernas imersas na água; por fim, um par constituído por um homem branco e uma mulher negra troca um beijo, montado num pato bravo. A este propósito, Portús (2008, p. 321) assinala que o viajante Antonio de Beatis, logo no ano de 1517, ter-se-á referido às figuras deste painel, como "coisas tão prazenteiras e fantásticas que de modo algum se poderiam descrever àqueles que não as tenham visto" .

Não obstante a caótica disposição das personagens neste painel central, a pintura é percorrida por um eixo vertical que divide a cena em duas partes semelhantes, o que the confere proporção. As cores luminosas e o ambiente despreocupado no qual é representada toda a cena completam a harmonia que caracteriza o jardim das delícias terrenas.

É deste modo que o painel central, ao configurar a concretização do mandamento que Deus enuncia no Éden enquanto apresenta Eva a Adão, parece dar continuidade ao painel volante esquerdo. Com efeito, a quantidade e a variedade de gentes e de animais, bem como de elementos naturais e arquitectónicos, idealmente distribuídos por toda a extensão desta parte do tríptico poderão ser interpretadas como a representação de um mundo harmonioso.

A frente do painel volante direito - com igual dimensão à do painel esquerdo -apresenta, segundo Bosing (2003), a visão mais violenta do Inferno de entre as pintadas por Bosch. Num cenário de pesadelo, vêem-se, ao fundo, edifícios que explodem e ardem

"Segundo alguns intérpretes da obra, este casal ilustra o provérbio dos Países Baixos "O prazer é frágil como o vidro" (AAVV, 2006). 
iluminados por estranhas fosforescências. Em primeiro plano, homens e mulheres sem qualquer veste no corpo são torturados com objetos de uso diário de proporções monstruosas. Neste painel, no qual dominam representações de aflição e sofrimento, "a atmosfera não podia ser mais demoníaca", como bem observa Quina (2005, p. 360).

Independentemente do seu significado não ser claro até aos dias de hoje, e das muitas interpretações que lhe são atribuídas - o Homem deixando-se levar pelo prazer dos sentidos, o abandono aos prazeres carnais ou a loucura do mundo rumo à ruína e à perdição -, o facto de Filipe II, católico e protetor da Igreja (Hofstätter \& Pixa, 1987), ter adquirido esta obra para a sua notável coleção de arte retira credibilidade a algumas explicações, segundo as quais o "Jardim das Delícias" constitui uma representação intencionalmente herética. Aliás, nos nossos dias, no Museu do Prado, acompanhando a exposição deste tríptico, encontra-se uma inscrição que revela a razão pela qual o soberano tanto apreciava o "Jardim das Delícias": a obra representava, segundo a sua interpretação, a diversidade do mundo.

\section{A diversidAde do MUNdo SOb A gOVERnAÇÃo de Filite II}

É Joly (1999) quem enfatiza a necessidade de nos colocarmos do lado da receção quando pretendemos analisar uma mensagem, já que sobre as intenções do autor pesam várias limitações de interpretação: em primeiro lugar, porque, em bom rigor, ninguém sabe o suficiente acerca do que o autor quis dizer; depois, porque o facto de não termos a certeza de que aquilo que compreendemos corresponde à ideia inicialmente formulada pode impedir-nos de apontar conclusões definitivas; por fim, porque ao próprio autor é impossível dominar toda a significação produzida pela sua mensagem. Assim, a interpretação de uma obra de arte deve incidir nas significações que a mesma provocou no recetor em determinadas circunstâncias, em vez de procurar descobrir a mensagem pré-existente.

Coloquemo-nos, pois, do lado do recetor, neste caso Filipe II, relacionando o seu perfil pessoal com as condições históricas em que se desenvolveu o seu longo reinado (1555-1598), de modo a descortinarmos um provável quadro de significações para a sua interpretação de "O Jardim das Delícias".

Personagem histórica controversa, sobre a qual se disse o melhor e o pior, Filipe II terá sido, à sua época, um dos homens mais informados sobre a diversidade do mundo que reconhecia na pintura de Bosch. Senhor de um império onde não se punha o Sol exerceu soberania sobre povos com culturas muito distintas nos mais diversos pontos do globo. A extensão dos seus senhorios explicava-se porque,

como herdeiro de seu pai, Carlos V, reinou sobre as coroas ibéricas de Aragão e Castela, o que fazia dele senhor dos vice-reinos da Nova Espanha (México) e do Peru, com outros territórios da Europa, como a Lombardia, a Sicília, Nápoles, a Sardenha, o Franco-Condado e os Países Baixos. A ascensão ao trono dos Avis em 1580 traz consigo a agregação de Portugal e do seu império ultramarino, o que deu à sua monarquia uma escala ainda 
mais universal; estendia-se da Europa à América, e da África à Ásia. (Bouza, 2005, p. 16)

Desta forma, o impressionante conjunto de territórios unidos sob o poder de Filipe II produziu trajetórias de vida de caráter global entre o seu infindável séquito de servidores - vice-reis, ministros, navegadores, embaixadores e outros políticos e diplomatas que se movimentaram pelos quatro cantos do mundo - consubstanciadas nos relatos de experiências pessoais e profissionais a que o soberano tinha acesso através de documentos que circulavam na ampla burocracia em que se baseava a sua governação. $O$ precioso arquivo documental, conservado até aos nossos dias, que Filipe II constituiu com o objetivo de tornar a sua administração mais eficaz, permite que historiadores contemporâneos coloquem em evidência este aspeto do seu reinado (Bouza, 2005).

O interesse do monarca pelos diferentes espaços do globo que constituíam o seu império é denunciado não só pelo facto de ter passado períodos de tempo significativos em todos os seus domínios na Europa, como também pelo conteúdo da correspondência que trocou com diversos interlocutores. A título de exemplo, Bouza (2005) destaca as missivas enviadas por Filipe às suas filhas - as infantas Isabel Clara Eugénia e Catarina Micaela - que haviam ficado em Madrid durante os dois anos que passou em Portugal (1581-1583). Nestas, o soberano descreve o que vê, o que lhe sucede, o que espera ou o que o surpreende, como é o caso dos diabos - uma espécie de espantalhos - que saíam à rua durante a procissão do Corpo de Deus e que, por se assemelharem a figuras de Hieronymus Bosch, pareciam bons e nada assustavam. A partir desta alusão, é possível depreender a importância assumida pelo artista enquanto referência estética de Filipe II e de sua família, assim como a influência que a sua obra exercia sobre o imaginário do monarca.

Não tendo visitado os seus vastos domínios fora da Europa, o que se afiguraria impossível à época, Filipe II possuía também uma elevada quantidade de informação, através de documentos escritos, sobre as estranhas gentes que os habitavam, bem como sobre os seus originais hábitos de vida ou as suas peculiares práticas religiosas. Sobre esta faceta de Filipe II, afirmava Magalhães (1993, p. 564): “dominando bem a Geografia, busca saber minuciosamente os espaços que governa, procurando estar habilitado a bem decidir... (sic)". Daí que o seu imaginário fosse dominado por uma conceção do mundo ampla e diversa que o soberano reconhece na extraordinária espacialidade do painel central de Bosch, no exotismo das relações interétnicas aí representadas e na espetacularidade dos elementos naturais e arquitetónicos que o compõem².

Já Mukarovski (1997) reparava, nas suas reflexões sobre estética, que a relação entre arte e conceção do mundo, embora tradicionalmente considerada simples e clara, necessitava de uma profunda revisão. Isto porque a conceção do mundo poderá significar não só a atitude espontânea que o Homem assume perante a realidade, num determinado espaço geográfico e num determinado período da história, como poderá

\footnotetext{
${ }^{2}$ De relembrar que, à época, os relatos acerca dos "novos mundos" causavam tal estranheza, a ponto de os elementos que compunham essas narrativas parecerem fantásticos ou espetaculares. Exemplos disso foram as obras escritas pelos espanhóis Amerigo Vespucci e Cabeza de Vaca ou pelo português Fernão Mendes Pinto.
} 
também representar uma ideologia ou ainda um sistema filosófico. O autor concluía que esta distinção, sem dúvida útil para o estabelecimento de três diferentes categorias de abordagem à relação entre arte e conceção do mundo - a abordagem noética, a abordagem ideológica e a abordagem filosófica -, não deveria ser rigorosamente adotada, sob pena de a mesma empobrecer a análise de uma ligação em que as três dimensões se confundem num todo.

Com efeito, a conceção do mundo de Filipe II não poderá ser totalmente compreendida se a reduzirmos à sua atitude pessoal perante uma realidade diversa que parecia admirar no reconhecimento que dela fazia na obra de Bosch. É Magalhães (1993, p. 564) quem se refere à "diversidade estrutural dos seus reinos e senhorios, cidades e vilas e grupos sociais" como um óbice ao exercício de um pleno poder por parte do monarca. Tal como observa Bouza (2005), a dispersão territorial dos seus domínios exigia a integração de espaços socioculturais de natureza muito distinta numa mesma monarquia, pelo que a capacidade de adaptação aos diferentes equilíbrios locais se revelava como condição determinante para o reforço da legitimidade da sua administração. $O$ protagonismo alcançado por Filipe II, através da adoção desta estratégia política de conveniência, relaciona a sua governação, ainda segundo o mesmo autor (Bouza, 2005, p. 17), "com a mundialização definitiva da presença europeia no globo, ou, em suma, com a consolidação plena de alguns meios e formas culturais ao serviço da comunicação e da difusão de notícias, ideias e opiniões". Na verdade, como bem observa Magalhães (1993, p. 563), nenhum outro soberano da época moderna conheceu uma autoridade tão extensa como a de Filipe II, "senhor de espaços imensos que o forçam a políticas várias, consoante os tempos e os lugares", tendo, para isso, exercido "o seu régio mandato, confiante em Deus, que tudo podia e tudo governava" (Magalhães, 1993, p. 564). Daqui se depreende uma filosofia integracionista bem reveladora de um outro prisma de análise que deveremos admitir para a compreensão da conceção do mundo que o monarca possuía. Assim, a diversidade onde cabem o exotismo, a originalidade e a singularidade presentes na conceção do mundo com que Filipe interpreta o "Jardim das Delícias" é, ao mesmo tempo, a diversidade com que o soberano procura consubstanciar a imensidão do seu império.

Todavia, nunca o poder de Filipe poderia ter sido tão extenso se o monarca não tivesse assumido a governação de toda a diversidade em que assentava a coroa portuguesa. Após o desaparecimento de D. Sebastião de Portugal, de quem era primo, na Batalha de Alcácer Quibir, em 1578, “logo toma as providências necessárias para se apresentar como herdeiro (...), escolhendo dedicado embaixador para iniciar em Lisboa as difíceis jogadas que seriam de esperar, pelo 'ódio natural' que em Portugal havia a Castela" (Magalhães, 1993, p. 564). Para isso, garante o apoio da Companhia de Jesus e de outras ordens religiosas, bem como dos grandes mercadores portugueses interessados em alargar os seus negócios, de forma direta e legal, às possessões castelhanas.

Entretanto, para enfrentar a oposição às suas pretensões, Filipe II decide abrir caminho para o trono português por via militar, tendo entrado em Portugal como rei legítimo, por via da força, no final do ano de 1580. Durante as Cortes de Tomar, em Abril 
de 1581, é finalmente investido da majestade lusitana, numa cerimónia que em todos os aspetos respeitou o protocolo da monarquia dos Avis. Esta seria a primeira de várias atitudes tomadas por Filipe II - agora também D. Filipe I de Portugal - para, no dizer de Magalhães (1993, p. 566), "mostrar e fazer aceitar que o seu governo era tão português e tão favorável aos interesses portugueses como os dos seus antecessores". De facto, o monarca passa a governar o seu império - agora com uma escala verdadeiramente planetária - a partir de Lisboa, onde permanece durante dois anos, sem que a trajetória coletiva do povo português conheça alterações significativas.

Apesar da sua política de adaptação aos equilíbrios locais - que, como foi já demonstrado, servia o interesse de legitimar a imensidão do seu poder - Filipe "está persuadido da sua missão divina como soberano" esforçando-se "constantemente por impor um absolutismo incondicional" (Hoftätter \& Pixa, 1987, p. 12). Exemplos disso foram as suas violentas ações de repressão ao protestantismo e às aspirações autonomistas em muitos dos seus domínios na Europa, a constituição da Armada Invencível contra a Inglaterra de Isabel I ou o prosseguimento da implacável conquista da América com o extermínio de populações ameríndias. Todos estes episódios tocaram o inferno que completa o tríptico no qual Filipe II interpretava a diversidade do mundo. Dever-se-á pois tomar em consideração o posicionamento ideológico de pendor absolutista que marcou a sua governação, de modo a completar a leitura da relação entre o "Jardim das Delícias" e a conceção do mundo com que o monarca se relacionava com a diversidade. Para além de ser alvo da sua atitude de admiração face à descoberta da novidade e de constituir a filosofia de equilíbrio estrutural para o seu extenso poder, a diversidade do mundo deveria também ser ideologicamente dominada pela força, mesmo que para isso fosse necessário recorrer à linguagem da violência.

Estas três diferentes dimensões da relação de Filipe II com a diversidade - que emergem da aplicação das três categorias de análise propostas por Mukarovsky à relação entre a obra de Bosch e a conceção do mundo demonstrada pelo monarca -, uma vez entretecidas, permitem interpretar um homem trespassado por complexas contradições e, ao mesmo tempo, capaz de elaborar a síntese do seu espaço e do seu tempo. Com efeito, é ele quem pontifica no espaço ibérico de Portugal e Espanha que, nos decénios precedentes ao seu reinado, haviam inaugurado um novo ciclo no percurso histórico da humanidade: um ciclo em que mundo se abre à sua própria diversidade através das primeiras grandes navegações intercontinentais. Por inerência, como bem observa Erlichman (2010), é ele também quem realiza a convergência dos dois imensos impérios ultramarinos que estas nações, as maiores potências da época, haviam erigido nos mais diversos lugares do mundo recentemente descoberto. Quem melhor do que Filipe II poderia personificar a teia de inevitáveis contradições que se colocava a um mundo tão admiravelmente novo?

Porém, será necessário atender ao facto de que a coexistência entre o paraíso imaginado num lugar a descobrir, o equilíbrio integracionista do jardim das delícias terrenas e o inferno da dominação pela força não constituiu uma inovação ou um exclusivo das práticas deste soberano, sobretudo quando se analisam as relações históricas 
entre detentores de poder e diversidade do mundo. Aliás, essa tríade contraditória de expectativas e de atitudes face ao diverso tem sido incessantemente replicada desde os primeiros encontros do humano com o desconhecido. O que constituiu uma situação excecional no espaço/tempo de Filipe II foi o facto de a descoberta noética, a filosofia da integração e a ideologia da dominação, enquanto conceções de relação com um mundo diverso, terem sido ampliadas à escala planetária por via da expansão marítima europeia, da qual portugueses, logo seguidos por espanhóis, foram os pioneiros.

É nesse cenário da centúria de Quinhentos, em que a verdadeira dimensão do orbe se revela à humanidade e os continentes que a separavam passam a estar permanentemente ligados pelo comércio marítimo, que certos autores (Erlichman, 2010; Modelski, 2005; Rodrigues \& Devezas, 2009) interpretam o primeiro episódio da narrativa evolutiva da globalização. Aliás, a teorização de Modelski (2005) sobre os ciclos longos da política global reconhece ao pioneirismo da expansão ibérica a formação do primeiro núcleo de liderança à escala planetária, consubstanciada na produção e na comunicação de conhecimento sobre a diversidade do mundo. A este propósito, salienta Fernández-Armesto acerca das grandes navegações de Colombo ou de Vasco da Gama que "na subsequente história do mundo, muito pouco pode ser compreendido fora deste contexto" (2010, p. 507). E o facto é que, daí em diante, assistimos a um processo de transformação estrutural em que o mundo que se abre à sua própria diversidade, ao mesmo tempo que começam a ser edificados os impérios coloniais europeus na América, na Ásia e em África.

\section{COMUNICAÇÃO INTERCULTURAL E DESFRAGMENTAÇÃo DA MEMÓRIA}

Aqui chegados, parece fazer sentido convocar uma ideia postulada por Canclini acerca da encruzilhada de histórias que nos foi legada pelas dinâmicas de descompartimentação do mundo3: que as tensões entre forças globalizantes e dinâmicas da interculturalidade "podem ser concebidas como uma relação entre a épica e o melodrama" (2007, p. 32). Ora, tal como Canclini, também outros autores (Dussel, 2012; Mignolo, 2000) reconhecem fortes limitações aos modelos dualistas de interpretação da realidade. Tais modelos, assentes em leituras dicotomizadas, têm contribuído para a construção de uma memória fragmentada, por sua vez incapaz de dar conta da compreensão do passado, bem como das tensões e dos conflitos que caracterizam o nosso tempo. A título de exemplo, poder-se-á esclarecer o modo como a memória do colonialismo português tem vindo a ser construída:

embora a memória sobre a colonização esteja bastante presente nas narrativas de ambas as partes, de facto os significados que the são atribuídos são distintos. Por exemplo, do lado do ex-colonizador observa-se um esquecimento ou não reconhecimento dos efeitos mais violentos da

\footnotetext{
${ }^{3}$ Este conceito prevalece hoje como alternativa ao conceito de "Descobrimentos", uma vez que este era considerado excessivamente eurocêntrico.
} 
expansão colonial (...). Da parte do ex-colonizado são os efeitos violentos da ação colonial que se tornam mais evidentes nas memórias analisadas, enfatizando os aspetos mais opressivos do colonialismo (escravidão, massacres). (Macedo, 2013, pp. 273-274)

Como alternativa aos modelos dualistas, propõe-se que a leitura crítica dos processos de interação entre diferentes culturas ocorridos a partir da expansão marítima europeia adote um modelo de análise mais amplo, baseado nas três conceções sobre a diversidade do mundo que Filipe II tão bem encarna e que o tríptico de Bosch tão bem simboliza: a descoberta, a integração e a dominação. Uma vez que a épica e o melodrama resultam de leituras opostas sobre processos de dominação, espera-se que esta proposta estabeleça um padrão de análise pluridimensional capaz de acolher várias perspetivas e, deste modo, contribuir para a construção de uma narrativa heterológica, despida de nacionalismos e de apropriações ideológicas. O mesmo é dizer que, com este modelo, se pretende dar mais um passo rumo a uma desfragmentação da memória que permita a abertura a outras possibilidades de recontar o passado 4 . Como bem observa Borges Coelho (2013), o passado não deve ser abordado como um tempo fechado, com uma história definitiva; pelo contrário, deve ser frequentemente revisitado e o seu estudo deve constituir um trabalho sob permanente reformulação.

Contudo, para cumprir tal objetivo, o modelo proposto deverá ser ensaiado atendendo a dois pressupostos fundamentais, que a seguir se apresentam. $O$ primeiro pressuposto é o de que este modelo de análise não se pode confinar a uma abordagem estritamente historiográfica, pese embora a sua relevância para a compreensão do passado. Por isso mesmo, deverão ser tomados em conta os seus preciosos contributos, sem que estes configurem a base exclusiva de um discurso crítico sobre a abertura do mundo à sua própria diversidade. Qualquer processo de transformação estrutural é, por natureza, pluridimensional, admitindo aspetos tão variados como os políticos, os económicos, os sociais ou os culturais que, por sua vez, se ramificam em componentes específicas como a geoestratégia e as relações internacionais, a agricultura e o comércio, a antropologia e a etnografia ou a religião e a língua. Daí, a necessidade de entretecer um discurso pluridisciplinar nas malhas dos vários olhares que nos são dados pelas diferentes disciplinas das ciências sociais e humanas. Neste sentido, dever-se-á enquadrar a abertura do mundo à sua própria diversidade na perspetiva mais vasta da comunicação intercultural, tal como a entendem Cabecinhas \& Cunha (2008), de modo a acolher as diversas leituras despoletadas pelas suas múltiplas dinâmicas de relação entre pessoas, bens e ideias. A partir desta perspetiva é possível dar conta de uma realidade processual em que se cruzam participantes de várias etnias, religiões e culturas, sem esquecer as condições de desigualdade com que estes interagem, as fronteiras que entre eles se interpõem e, finalmente, a enorme distância que separa as suas inter-relações reais da sua suposta

\footnotetext{
${ }^{4}$ Sobre outras possibilidades de recontar o passado, é Khan (2016) quem se refere ao "dever de pós-memória", ou seja, à possibilidade de resgate de experiências e de narrativas contadas por gente que se tem mantido em silêncio. Na opinião da autora, se o "dever de pós-memória" não for cultivado, esse património acabará por não deixar qualquer evidência para a posterioridade.
} 
mistura. Importa sublinhar, portanto, que nesta perspetiva, o objecto de estudo não será tanto o facto histórico, mas antes o processo de comunicação intercultural ocorrido no contexto desse mesmo facto.

Convém, contudo, frisar que a perspetiva da comunicação intercultural não dispensa uma abordagem séria à problemática da alteridade. Por isso mesmo, impõe-se um retorno à obra de Todorov (1991), autor que defende que a alteridade só pode ser entendida quando se observam as interdependências entre as suas três dimensões: a dimensão axiológica, a dimensão praxiológica e a dimensão epistémica. $\mathrm{Na}$ dimensão axiológica, são os juízos de valor em relação ao outro que entram em jogo. As ações concretas para com esse outro - assimilação, submissão ou indiferença, por exemplo - situam-se na dimensão praxiológica. Por fim, o nível de conhecimento sobre a identidade daquele que me é exterior define a dimensão epistémica. Note-se, entretanto, que à dimensão axiológica da compreensão das relações de alteridade poderá ser associada a pulsão da dominação; com a sua dimensão praxiológica, poderão ser relacionados os diversos processos de integração; por fim, à sua dimensão epistémica poderá estar ligada a experiência da descoberta.

É por isso mesmo que a abordagem da comunicação intercultural não deve ser confundida com a abordagem contemporânea do diálogo de culturas, uma vez que esta última constitui, no dizer de Todorov (1991, p. 246), "um diálogo onde ninguém tem a última palavra, onde nenhuma das vozes reduz a outra ao status de um mero objeto, e onde se tira vantagem de sua exterioridade ao outro". Ainda que bem intencionada, a ótica do diálogo de culturas, ao excluir os processos comunicacionais em que uma das partes se coloca em posição de superioridade (ou inferioridade) relativamente à outra, compromete a compreensão das principais dinâmicas de interação entre diferentes culturas. $E$, tal como se encontra amplamente documentado, os sucessos e os insucessos dos protagonistas do processo de abertura do mundo a si mesmo, ao longo de mais de cinco séculos de história, ficaram a dever-se, em boa parte, aos diferentes padrões de comunicação que utilizaram com os mais diversos interlocutores.

O segundo pressuposto para a aplicação deste modelo, e que serve para reforçar a importância do primeiro, parte da ideia defendida por Ferro (2004) de que não existe uma verdade histórica válida para todos. Sobre cada acontecimento, cada povo ou cada nação sobrepõem-se - quando não se opõem - determinações diversas, não sendo certo que uma tenha mais legitimidade do que as outras. Daí a necessidade de analisar a abertura do mundo à sua própria diversidade a partir não só da confrontação dos diversos pontos de vista produzidos na Europa, como também dever-se-á ter em conta as perspetivas tradicionalmente silenciadas, ou seja, aquelas que tendo sido interditadas por muito tempo, são-nos hoje colocadas a partir de África, da América ou da Ásia. Todavia, para além de menos numerosas e de menos difundidas, estas abordagens não europeias adquirem muitas vezes, no entendimento de Ferro (2004, p. 16), uma "função terapêutica"; o mesmo é dizer que, face à Europa, as sociedades do resto do mundo descolonizam a sua própria história, quase sempre com os mesmos instrumentos dantes utilizados pelo colonizador. É deste modo, construindo seletivamente uma memória 
inversa daquela que foi também seletivamente desenvolvida pelos interesses europeus, que novas versões da história procuram reconciliar estas sociedades com o seu próprio passado5.

Em todo o caso, tal como afirma Said, a interpretação do passado do colonialismo ultramarino, pressupõe a oposição de "duas perspectivas diferentes (...), uma linear e dominadora, a outra contrapontual e muitas vezes nômade (sic)" (1993/2011, p. 29). E embora o autor se incline para uma maior valorização da segunda, não deixa de notar que, quer seja contada por quem colonizou, quer seja contada por quem foi colonizado, nenhuma narrativa sobre este tipo de experiência é edificante.

Apesar destas observações, nem o entendimento de Ferro, nem o entendimento de Said se orientam no sentido de que este passado não deva ser analisado; bem pelo contrário, ambos os autores sugerem que as narrativas sobre a expansão marítima e os impérios coloniais europeus sejam recompostas, ora integrando acontecimentos e lugares que escaparam à memória (no caso de Ferro), ora a partir da perspetiva que nos é dada hoje pela abordagem pós-colonial das ciências sociais (no caso de Said).

$\mathrm{Na}$ mesma linha de pensamento, é McMillin (2009) quem defende a ideia de que para se abordar a atual globalização é preciso escrutinar a história e as práticas contemporâneas no mapa simultaneamente temporal, espacial e ideológico que nos é dado pelos estudos pós-coloniais. Inicialmente concebidos como uma metodologia, mais do que como uma teoria, os estudos pós-coloniais desenvolveram-se para analisar a forma como as sociedades outrora colonizadas se adaptaram ao discurso imperial, bem como as impressões legadas pelo colonialismo na cultura das mesmas. A relevância desta abordagem é enfatizada pela autora a partir da constatação de que as consequências do colonialismo - que se fazem sentir até aos dias de hoje - são coletivamente partilhadas pelas sociedades que o viveram. Daí a necessidade de tomá-la em linha de conta quando se pretende atender às atuais condições das sociedades contemporâneas com um passado colonial.

Todavia, há a considerar que o pós-colonialismo não está isento de pontos fracos, como bem notou Almeida (2002). Tendo emergido no cruzamento da crítica literária e dos estudos culturais - por sua vez, herdeiros da teoria crítica e do pós-estruturalismo -, o pós-colonialismo constituiu-se como abordagem alternativa aos padrões de conhecimento estabelecidos pelo domínio ocidental, sobretudo no que toca à produção historiográfica e ao estudo de identidades sociais. Para além da recusa de todas as narrativas-mestras e do eurocentrismo que delas emana, a abordagem pós-colonial repudia dicotomias como "centro/periferia" ou "primeiro mundo/terceiro mundo" alegadamente criadas pelo colonialismo, consubstanciando uma nova constituição discursiva do mundo. Por isso mesmo, o pós-colonialismo mais radical corre o risco de substituir a verdade única do ex-colonizador pela verdade única do ex-colonizado, podendo, assim, contribuir para fortalecer a "Escola do ressentimento" a que se referia Bloom (1997, p. 31).

\footnotetext{
5 Ferro (2004) refere, a título de exemplo, que a história ensinada às crianças africanas tende a glorificar o esplendor dos grandes impérios existentes no seu continente antes da chegada de europeus, por contraposição ao atraso e à decadência da Europa feudal da mesma época.
} 
É deste modo que o segundo pressuposto procura robustecer a perspetiva da comunicação intercultural, sem que isso signifique a recusa absoluta do eurocentrismo ou dos discursos "terapêuticos" pós-coloniais. Tal recusa faria com que o objetivo para o qual se pretende contribuir - ou seja, a desfragmentação da memória - se perdesse de vista ou se quedasse pelo caminho.

\section{Conclusão}

Tendo em conta que o cruzamento do presente independente com o passado colonial gera, a maior parte das vezes, equívocos de difícil resolução e que daí resulta a produção de narrativas duais, por si só incapazes de nos dar conta da realidade, foi aqui apresentada a proposta de um modelo analítico alternativo para a leitura crítica das dinâmicas de comunicação entre culturas que se estabeleceram desde que o mundo se tornou global. Com efeito, o mundo em que vivemos hoje é herdeiro, no seu melhor e no seu pior, da expansão marítima e dos impérios coloniais europeus. E esse foi, sem dúvida, um movimento que, tendo contribuído para que o mundo abrisse as portas à sua própria diversidade, naturalmente, não tinha como controlá-la.

A proposta aqui apresentada deverá desenvolver-se a partir da perspetiva da comunicação intercultural e da interconexão dos vários contributos, dos vários olhares e das várias vozes envolvidos nesse movimento, adotando para o efeito três categorias analíticas inspiradas pelas três conceções sobre a diversidade do mundo que Filipe II interpretou na obra "Jardim das Delícias": a descoberta, a integração e a dominação.

Todavia, dificilmente poder-se-á conceber a perspetiva da comunicação intercultural fora de um quadro de disputa entre forças desiguais, uma vez que, em todos os processos de comunicação entre culturas, há sempre interlocutores mais fortes e interlocutores mais fracos. A alteridade vai perdendo terreno como traço característico do nosso tempo, enquanto o passado ficou marcado pela falta de reconhecimento do outro enquanto sujeito. Quer isto dizer que a proposta aqui apresentada, embora assuma a ambição de se constituir como um modelo alternativo de análise da relação entre forças globalizantes e dinâmicas de interculturalidade, deve ser entendida sem qualquer tipo de messianismo. Deve ser entendida, antes, como um possível instrumento de desfragmentação da memória que nos ajude a compreender melhor o quadro de crise estrutural e de conflitualidade crescente que vivemos nos nossos dias. Isto porque o mundo, diverso que é, nunca será um paraíso; mas também não tem que ser o violento inferno do tríptico de Bosch.

\section{REFERÊNCIAS BIBLIOGRÁFICAS}

AAVV (2006). A Grande História da Arte - Renascimento e Maneirismo (3). Público.

Almeida, M. V. (2002). O Atlântico pardo. Antropologia, pós-colonialismo e o caso "lusófono". In C. Bastos; M. V. Almeida \& B. Feldman-Bianco(Eds.), Trânsitos Coloniais: Diálogos Críticos Luso-Brasileiros (pp. 2337). Lisboa: Imprensa de Ciências Sociais. 
Bloom, H. (1997). O cânone ocidental. Lisboa: Temas e Debates.

Borges Coelho, J. P. (2013). Politics and contemporary history in Mozambique. A set of epistemological notes. Kronos, 39(1), 20-31.

Bosing, W. (2003). Hieronymus Bosch. Entre o Céu e o Inferno. Köln: Tashen

Bouza, F. (2005). D. Filipe I. Coleção Reis de Portugal. S/l: Círculo de Leitores e Centro de Estudos dos Povos e Culturas de Expressão Portuguesa.

Cabecinhas, R. \& Cunha, L. (2008). Da importância do diálogo ao desafio da interculturalidade. In R. Cabecinhas \& L. Cunha, Comunicação Intercultural. Perspetivas, Dilemas e Desafios (pp. 7-12). Porto: Campo das Letras.

Canclini, N. G. (2007). A globalização imaginada. São Paulo: Editora Iluminuras.

Dussel, E. (2012). Transmodernity and interculturality: an interpretation from the perspective of philosophy of liberation. Transmodernity, 1(3), 28-59.

Erlichman, H. J. (2010). Conquest, tribune and trade: the quest for precious metals and the birth of globalization. Nova lorque: Prometheus Books.

Fernández-Armesto, F. (2010). A expansão portuguesa num contexto global. In F. Bethencourt \& D.R. Curto (Eds.), A Expansão Marítima Portuguesa, 1400-1800 (pp. 491-524). Lisboa: Edições 70.

Ferro, M. (2004). Comment on raconte l'histoire aux enfants à travers le monde (nouvelle édition revue). Paris: Éditions Payot.

Hofstätter, H. H. \& Pixa, H. (1987). História universal comparada - De 1550 a 1900 (Volume VIII). Lisboa: Resomnia Editores.

Joly, M. (1999). Introdução à análise da imagem. Lisboa: Edições 70.

Khan, S. (2016). A pós-memória como coragem cívica. Palavra de ordem: resistir, resistir, resistir. Comunicação e Sociedade, 29, 353-364. doi: http://dx.doi.org/10.17231/comsoc.29(2016).2424

Macedo, I. (2016). Os jovens e o cinema português: a (des)colonização do imaginário? Comunicação e Sociedade, 29, 271-289. doi: http://dx.doi.org/10.17231/comsoc.29(2016).2420

Magalhães, J. R. (1993). Filipe II (I de Portugal). In J. R. Magalhães (Ed.), No Alvorecer da Modernidade (pp. 563-570). Coleção História de Portugal. Lisboa: Editorial Estampa.

McMillin, D. C. (2009). Mediated identities. Youth, agency Q globalization. Nova lorque: Peter Lang Publishing.

Mignolo, W. (2000). Local histories / Global designs: coloniality, subaltern knowledges, and border thinking. Princeton: Princeton University Press.

Modelski, G. (2005). Long-term trends in world politics. Journal of World-Systems Research, 11(2), 195-206.

Mukarovsky, J. (1997). Escritos sobre estética e semiótica da arte. Lisboa: Editorial Estampa.

Portús, E. Z. (Ed.) (2008). O guia do Prado. Madrid: Museo Nacional del Prado.

Quina, J. (Ed.) (2005). Museu do Prado. Colecção Museus do Mundo. S/l: Edições Planeta Agostini. 


\section{FinANCIAMENTO}

Este artigo foi escrito ao abrigo da bolsa de pós-doutoramento atribuída pela Fundação para a Ciência e Tecnologia, financiada pelo Estado Português e pela União Europeia, com a Referência SFRH/BPD/103706/2014.

\section{NOTA BIOGRÁFICA}

Lurdes Macedo é doutorada em Ciências da Comunicação pela Universidade do Minho. É também investigadora do Centro de Estudos de Comunicação e Sociedade da mesma universidade, tendo integrado a equipa do projeto "Narrativas identitárias e memória social: a (re)construção da lusofonia em contextos interculturais", entre 2009 e 2013. Foi investigadora convidada do Núcleo de Estudos Lusófonos da Universidade Presbiteriana Mackenzie de São Paulo (Brasil) em 2009, 2010, 2011 e 2012, bem como do Radio, Television and Film Department da Universidade do Texas em Austin (E.U.A.) em 2011. Foi co-editora do Anuário Internacional de Comunicação Lusófona em 2010 e 2011 e do e-book Interfaces da Lusofonia em 2014. Tem mais de vinte artigos publicados em revistas científicas nacionais e internacionais. Foi assistente convidada da Escola Superior de Educação do Instituto Politécnico de Viseu entre 2009 e 2012. Atualmente, é professora auxiliar da Universidade Lusófona do Porto e na Universidade Politécnica de Maputo (Moçambique). Atuou por diversas vezes como professora convidada em quatro universidades brasileiras - Universidade de São Paulo, Pontifícia Universidade Católica de São Paulo, Universidade Presbiteriana Mackenzie de São Paulo e Universidade Federal de Minas Gerais - entre 2009 e 2012. Paralelamente à atividade como docente universitária e investigadora, integrou equipas em projetos de consultoria, nomeadamente na área do desenvolvimento.

E-mail:mlmacedo7ı@gmail.com

Centro de Estudos de Comunicação e Sociedade, Universidade do Minho, ICS, Campus de Gualtar, 4710-057, Braga, Portugal

* Submetido: 15-10-2016

* Aceite: 21-01-2017 